ORIGINAL ARTICLE

\section{A rare variant of the leptin gene has large effects on blood pressure and carotid intima-medial thickness: a study of 1428 individuals in 248 families}

\author{
N Gaukrodger*, B M Mayosi†, H Imrie, P Avery, M Baker, \\ J M C Connell, H Watkins, M Farrall, B Keavney
}

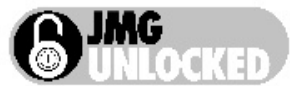

This article is available free on JMG online via the JMG Unlocked open access trial, funded by the Joint Information Systems Committee. For further information, see http://img.bmijournals.com/cgi/content/ full $/ 42 / 2 / 97$
See end of article for authors' affiliations

Correspondence to:

Correspondence to:
Bernard Keavney, Institute of Human Genetics, Central Parkway,

Newcastle upon Tyne NE1 3BZ, UK; b.d.keavney@ ncl.ac.uk

Revised version received 15 December 2004 Accepted for publication 7 January 2005

\begin{abstract}
Background: Rare mutations in the leptin (LEP) gene cause severe obesity. Common polymorphisms of LEP have been associated with obesity, but their association with cardiovascular disease has been little studied. We have examined the impact of both common and rare polymorphisms of the LEP gene on blood pressure (BP), subclinical atherosclerosis as measured by carotid intima-medial thickness (CIMT), and body mass index (BMI) in a large family study.

Methods: Five polymorphisms spanning LEP were typed in 1428 individuals from 248 nuclear families. BP, CIMT, BMI, and plasma leptin were measured.

Results: The polymorphisms typed captured all common haplotypes present at LEP. There was strong association between a rare polymorphism in the $3^{\prime}$ untranslated region of LEP (C538T) and both pulse pressure $(p=0.0001)$ and CIMT $(p=0.008)$. C/T heterozygotes had a $22 \%$ lower pulse pressure and a $17 \%$ lower CIMT than C/C homozygotes. The polymorphism accounted for $3-5 \%$ of the population variation in pulse pressure and CIMT. There was no association between any LEP polymorphism and either $\mathrm{BMI}$ or plasma leptin level.

Conclusions: This large family study shows that the rare T allele at the C538T polymorphism of LEP substantially influences pulse pressure and CIMT, but does not appear to exert this effect through actions on plasma leptin level or BMI. This suggests that autocrine or paracrine effects in vascular tissue may be important physiological functions of leptin. This study also provides evidence that rare polymorphisms of particular genes may have substantial effects within the normal range of certain quantitative traits.
\end{abstract}

eptin is the central hormone in the adiposity-sensing pathway. Circulating leptin is produced principally by -adipocytes and functions as a satiety signal; coding or splice site mutations in the gene encoding leptin $(L E P)$ which render the leptin protein unable to signal through its receptor, produce severe childhood onset obesity. ${ }^{12}$ However, such coding sequence variation in LEP is extremely rare in general populations. ${ }^{3}{ }^{4}$ Evidence for association between commoner polymorphisms, mainly in the $5^{\prime}$ region of $L E P$, and obesity has been sought in several previous studies; significant association has been found in some but not in other studies, ${ }^{5-8}$ and this issue remains controversial.

Although obesity is a risk factor for a variety of conditions, cardiovascular disease is the principal source of morbidity and mortality in obese persons. Thus far, the cardiovascular effects of leptin, and the possible existence of obesity independent associations between polymorphisms of LEP and cardiovascular risk, have been relatively little studied. Blood pressure (BP) is a major risk factor for cardiovascular disease, and the contribution of genes to the population variability of BP is significant. ${ }^{9}$ A number of cross sectional studies suggest that increased arterial stiffness, measured by a variety of techniques, is an independent risk factor for cardiovascular disease ${ }^{10-14}$; pulse pressure is a simply measured indicator of increased arterial stiffness with a prospectively validated relationship to cardiovascular risk in large numbers of subjects. ${ }^{15}$ Measurement of the intimamedial thickness (IMT) of the carotid artery is a non-invasive method of assessing the extent of atherosclerosis in presymptomatic subjects which is strongly associated with the future occurrence of cardiovascular events in prospective studies. ${ }^{16}$ We have examined the relationship between both common and rare polymorphisms of the leptin gene and BP, carotid intima-medial thickness (CIMT), and body mass index (BMI) in a large family based association study.

\section{METHODS}

The collection strategy of this family study has been previously described. ${ }^{17} 18$ Briefly, families were ascertained between 1993 and 1997 through a proband with essential hypertension. In order to be suitable for the study, families were required to consist of at least three siblings clinically assessable for BP if at least one parent of the sibship was available to give blood for DNA analysis, and to consist of at least four assessable siblings if no parent was available for DNA analysis. Families were extended to include the nuclear families of additional individuals in the sibship who were hypertensive, where applicable. Thus, the majority (65\%) of the individuals in the family collection have BP within the normal range, and most families consist of single sibships.

Blood pressure was measured using ambulatory monitoring for a period of $24 \mathrm{~h}$ (A\&D TM242l, Takeda Medical, Toyko, Japan) as previously described.$^{19}$ A full clinical history was taken, which included the subject's medical history and lifestyle factors including consumption of alcohol and tobacco, and habitual physical exercise. Anthropometric

Abbreviations: $\mathrm{BMl}$, body mass index; $\mathrm{BP}$, blood pressure; CIMT, carotid intima-medial thickness; IMT, intima-medial thickness; WHR, waist to hip ratio 
Table 1 Primers and restriction enzymes used for genotyping

\begin{tabular}{llll}
\hline Polymorphism & Forward primer & Reverse primer & Restriction enzyme \\
\hline G2548A & 5' TITCCTGTAATTITCCCGTGAG3' & 5'AAAGCAAAGACAGGCATAAAAA3' & Hhal $^{\prime}$ \\
C188A & 5'CAACGAGGGCGCAGCCGTAT3' & 5'AGTGTGCACCTCGCGGGGCCT3' & Asd $^{\prime}$ \\
A19G & 5'GCCCCGCGAGGTGCACACTG3' & 5'GGGCCCTGTGGCCTGCCAAG3' & MspA1I $^{\prime}$ \\
rs2060713 & 5'CCAGGCCTGATAAAGGAG3' & 5'CATTIAGGAGCTGCCATIITC3' & BsiHKAl $^{\prime}$ \\
C538T & 5'CGACCTGGAGAACCTCCG3' & 5'GTCCTGGATAAGGGGTGT3' & HpyCH4IV \\
\hline
\end{tabular}

measurements including height, weight, and waist and hip measurement were noted (waist measured at the natural waist, and hip measured at the level of the greater trochanters). Blood was drawn into a variety of anticoagulants for plasma and DNA analysis. In all, 1428 individuals from 248 families participated in the study. Between 1997 and 2000, 955 individuals from 220 families re-attended for ultrasonic measurement of CIMT. This was performed using a $7.5 \mathrm{MHz}$ linear array transducer on a Hewlett-Packard Sonos 5500 machine, as previously described. ${ }^{20-22}$ A total of 856 individuals from 220 families had technically satisfactory measurements.

Plasma leptin was measured on heparinised samples using a commercially available ELISA kit (Linco Research, St Charles, MO) with sensitivity $0.5 \mathrm{ng} / \mathrm{ml}$, intra-assay precision $2.6-4.6 \%$, and inter-assay precision $2.6-6.2 \%$. Five polymorphisms spanning the leptin gene in non-translated sequence were genotyped, four of which (G2548A, C188A, A19G, C538T) had been studied by previous investigators, and one of which (rs2060713, a C/T substitution in intron 1) had not previously been studied (fig 1). All polymorphisms were typed by PCR followed by restriction enzyme digestion and agarose gel electrophoresis to resolve fragments, using primer pairs and restriction enzymes shown in table 1. Controls of known genotype were included in each genotyping plate.

Mendelian inheritance of all genotypes was checked using PedCheck. ${ }^{23}$ Possible genotyping errors not producing Mendelian inconsistencies were detected by examining the families for recombination in this short genomic segment using Merlin..$^{24}$ Haplotype frequencies across the leptin gene were calculated using Fugue. ${ }^{25}$ Phenotypes of interest were examined for normality and log transformed where necessary. Significant covariates of these phenotypes were then determined by linear regression using MINITAB; the adjusted values from these regressions were used in the genetic analysis. Association between genotypes at the typed markers and the adjusted phenotypes was assessed in the families by calculating identity by descent vectors for each individual using Merlin followed by variance components analysis using QTDT. ${ }^{26}$ In the present analyses, only those individuals in whom an ambulatory BP recording without drug treatment for hypertension was available were included. Since previous reports had suggested association of LEP polymorphisms with BMI either only in men or only in women, subsidiary analyses involving men and women separately were performed for BMI. Bivariate models to assess the evidence for pleiotropic effects of leptin variants were fitted using PAP version $5.0 .{ }^{27}$

\section{RESULTS}

Baseline demographics of the population are shown in table 2 . The median BMI was representative of a UK general population unselected for obesity, and the median IMT values were within the normal population range $(0.4-$ $1.0 \mathrm{~mm}$ ). Age, gender, alcohol consumption (in units per week), smoking (coded current/former/never), and habitual physical exercise accounted for $5-50 \%$ of the population variability in the different phenotypes of interest (table 2).

Genotyping was successful in $>97 \%$ of family members at all polymorphisms, with insufficient remaining DNA sample the principal reason for dropout. The estimated genotype error rate was $<1 \%$ for all polymorphisms. Allele frequencies at all polymorphisms satisfied Hardy-Weinberg equilibrium, and agreed closely with allele frequencies described at these polymorphisms in Caucasians in previous studies (table 3 ). The $\mathrm{T}$ allele of the C538T polymorphism in the 3'UTR of the $L E P$ gene (LEPC538T) was rare, occurring in only 14 heterozygote members of the population from seven families and no homozygotes $\left(\mathrm{p}_{\mathrm{T}}=0.005\right)$. Linkage disequilibrium in the region was strong; only five of a possible 32 haplotypes had frequencies $>0.6 \%$ (table 4 ). These haplotype data are in close agreement with a recent report from Jiang et al in a smaller but more intensively genotyped Caucasian population. ${ }^{8}$

No highly significant association between any of the polymorphisms and either systolic or diastolic BP was observed, though there was a borderline trend towards lower

Table 2 Characteristics of the study population

\begin{tabular}{|c|c|c|c|c|c|c|c|}
\hline Variable & $n$ & Min & LQ & Median & UQ & $\operatorname{Max}$ & $R^{2} \dagger$ \\
\hline Age (years) & $1425^{*}$ & 18.7 & 35.7 & 50.9 & 60.9 & 90.7 & - \\
\hline$B M I\left(\mathrm{~kg} / \mathrm{m}^{2}\right)$ & 1402 & 16.7 & 23.1 & 25.4 & 28.2 & 51.8 & 15.2 \\
\hline WHR & 1357 & 0.56 & 0.78 & 0.85 & 0.91 & 1.22 & 48.7 \\
\hline Plasma leptin (ng/ $\mu l)$ & 1319 & 1.1 & 4.6 & 8.6 & 15.3 & 116.6 & 46.4 \\
\hline Daytime systolic (mm Hg) & 958 & 94.2 & 121.1 & 131 & 144.1 & 214.0 & 20.4 \\
\hline Daytime diastolic $(\mathrm{mm} \mathrm{Hg})$ & 958 & 54.0 & 72.0 & 78.6 & 88.0 & 119.9 & 17.9 \\
\hline Daytime pulse pressure $(\mathrm{mm} \mathrm{Hg})$ & 958 & 29.0 & 45.0 & 51.4 & 58.4 & 105.0 & 14.2 \\
\hline Clinic pulse pressure $(\mathrm{mm} \mathrm{Hg})$ & 928 & 24.0 & 43.7 & 50.5 & 60.9 & 112.0 & 21.8 \\
\hline Nighttime pulse pressure $(\mathrm{mm} \mathrm{Hg})$ & 770 & 9.0 & 40.0 & 46.0 & 52.7 & 86.0 & 4.5 \\
\hline Mean IMT $(\mathrm{mm})$ & 854 & 0.42 & 0.65 & 0.76 & 0.91 & 2.17 & 38.9 \\
\hline $\operatorname{Max}$ IMT (mm) & 856 & 0.44 & 0.71 & 0.83 & 1.00 & 2.53 & 37.3 \\
\hline
\end{tabular}

*Of which $52.4 \%$ were female and $36.1 \%$ were classified as hypertensive; tproportion of variability explained by correction for environmental variables (that is, age, gender, alcohol consumption, smoking behaviour, exercise taken). All variables were log transformed before correction except WHR. This was done to approximately normalise the distributions.

$L Q$, quartile; $U Q$, upper quartile; WHR, waist to hip ratio. 


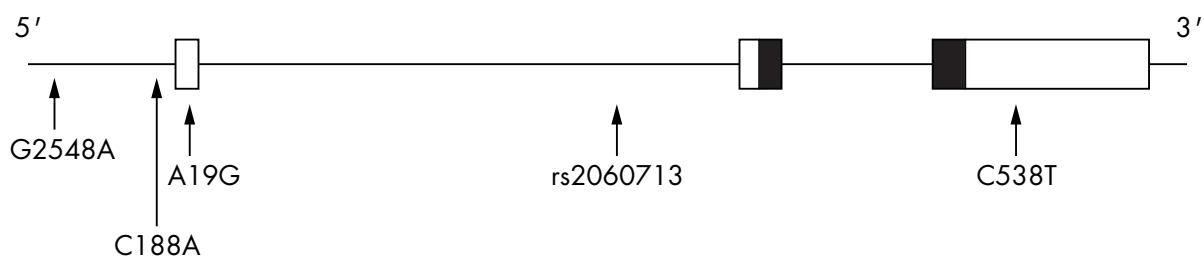

Figure 1 Position of five polymorphisms typed across $20 \mathrm{~kb}$ spanning the leptin (LEP) gene on chromosome 7. Black shading indicates coding sequence.

systolic BP with the $\mathrm{T}$ allele of LEPC538T $(\mathrm{p}=0.025)$. The $\mathrm{T}$ allele of LEPC538T was highly significantly associated with a lower pulse pressure $(p=0.0001)$ : even though Bonferroni correction for multiple analyses is almost certainly overconservative in this situation, ${ }^{28}$ this $\mathrm{p}$ value remains significant after such correction for 15 analyses (corrected $\mathrm{p}$ value $=0.005$ ). CT heterozygotes had a $22.2 \%$ (standard error $4.8 \%$ ) lower pulse pressure than CC homozygotes. The T allele was also associated with a significantly lower CIMT $(\mathrm{p}=0.0076)$; CT heterozygotes had a $17.6 \%(6.2 \%)$ lower maximum CIMT. CIMT and pulse pressure were modestly, though significantly, correlated $(\mathrm{r}=0.15, \mathrm{p}<0.0001)$. We examined the evidence for pleiotropic effects of LEPC538T on these two traits using PAP. In a bivariate, measured genotype model of daytime pulse pressure and CIMT, the C538T variant was significantly associated with both traits $(p<0.05)$; a minor proportion of the correlation between the traits was accounted for by the pleiotropic effects of the variant (table 5). LEPC538T accounted for 3-5\% of the observed population variation in both pulse pressure and carotid IMT. There was no significant association between any LEP polymorphism and BMI either in the whole population, or in men and women considered separately. Nor was there significant association between any LEP polymorphism and plasma leptin level.

\section{DISCUSSION}

This large family based association study shows that the rare $\mathrm{T}$ allele of the C538T polymorphism in the 3'UTR of the LEP gene is associated with lower arterial stiffness (as measured by pulse pressure) and lower carotid IMT. Although this variant accounted for only about $5 \%$ of the population

Table 3 Genotype and allele frequencies at five SNPs of the LEP gene

\begin{tabular}{llrl}
\hline SNP & Genotype & Frequency & \\
\hline G2548A & G/G & 406 & $\mathrm{P}_{\mathrm{G}}=0.546$ \\
& $\mathrm{G} / \mathrm{A}$ & 704 & $\mathrm{P}_{\mathrm{A}}=0.454$ \\
& A/A & 279 & \\
C188A & All & 1389 & \\
& C/C & 1243 & $\mathrm{P}_{\mathrm{C}}=0.947$ \\
& C/A & 148 & $\mathrm{P}_{\mathrm{A}}=0.053$ \\
& A/A & 0 & \\
$\mathrm{~A} 19 \mathrm{G}$ & All & 1391 & \\
& $\mathrm{G} / \mathrm{G}$ & 548 & $\mathrm{P}_{\mathrm{G}}=0.619$ \\
& $\mathrm{G} / \mathrm{A}$ & 630 & $\mathrm{P}_{\mathrm{A}}=0.381$ \\
& A/A & 217 & \\
2060713 & All & 1395 & \\
& C/C & 1241 & $\mathrm{P}_{\mathrm{C}}=0.951$ \\
& C/T & 129 & $\mathrm{P}_{\mathrm{T}}=0.049$ \\
& T/T & 3 & \\
C538T & All & 1373 & \\
& C/C & 1362 & $\mathrm{P}_{\mathrm{C}}=0.995$ \\
& C/T & 14 & $\mathrm{P}_{\mathrm{T}}=0.005$ \\
& T/T & 0 & \\
& All & 1376 & \\
& & &
\end{tabular}

variability of these traits (because of its low frequency), it had a large effect in carriers, lowering both pulse pressure and IMT by around $20 \%$. Such effects would be expected to have clinical significance in carriers with respect to risk of cardiovascular events. ${ }^{15}{ }^{16}$ Although LEPC538T is non-coding, similarly positioned variants in the 3' UTR of other genes are known to have important effects on their expression..$^{29} 30$ LEPC538T was not associated with BMI or with plasma leptin level, suggesting that its effects on arterial stiffness and atherosclerosis may be mediated through a local (autocrine or paracrine) mechanism in vascular tissue. We found evidence in favour of a pleiotropic effect of LEPC538T on both pulse pressure and carotid IMT, suggesting that leptin may be involved in a pathway common to the development of increased arterial stiffness and the development of atherosclerosis. This is supported by evidence that leptin activates platelets and promotes thrombosis and neointimal thickening after vascular injury in mouse models, and thus may be involved in atheromatous plaque growth by repeated rupture and repair. ${ }^{31}$ In the only previous report involving LEPC538T, no association between genotype and obesity was found in 200 obese and 65 non-obese Finnish subjects. ${ }^{33}$ However, that study did not examine cardiovascular risk phenotypes. Only one previous, much smaller study has investigated the relationship between leptin polymorphisms and BP. Shintani et al investigated a tetranucleotide repeat in the $3^{\prime}$ region of $L E P$ in a study of 205 hypertensive and 117 normotensive subjects; when alleles at this repeat were categorised into shorter and longer groups, a modest association between genotype and hypertension was demonstrated. ${ }^{34}$ No previous study has examined the relationship between LEP polymorphisms and the severity of atherosclerosis as measured by carotid IMT.

The polymorphisms we typed at LEP captured all common haplotype variation across the gene, and no association between genotype at any polymorphism and either BMI or plasma leptin was present. Several previous studies have examined the relationship between leptin polymorphisms and obesity phenotypes, and the results are discordant, with some studies claiming association and others not. With the exception of the recent study by Jiang et al, ${ }^{8}$ the present study is the only one to have assessed all common haplotypes of $L E P$, and it is also the largest study so far. It should, however, be noted that most previous studies have selected obese cases

Table 4 Common haplotypes spanning the LEP gene

\begin{tabular}{llllll}
\hline $\begin{array}{l}\text { Haplotype } \\
\text { frequency }\end{array}$ & G2548A & C188A & A19G & rs2060713 & C538T \\
\hline 0.40 & A & C & G & C & C \\
0.31 & G & C & A & C & C \\
0.16 & G & C & G & C & C \\
0.05 & A & C & A & C & C \\
0.04 & G & A & G & T & C \\
\hline
\end{tabular}


Table 5 Bivariate measured genotype analysis of LEPC538T polymorphism, pulse pressure, and carotid IMT

\begin{tabular}{|c|c|c|c|}
\hline \multicolumn{2}{|l|}{ Trait } & \multirow{2}{*}{$\begin{array}{l}\text { Estimate (SE) } \\
1.00(0.31) \\
0.24(0.06)\end{array}$} & \multirow{2}{*}{$\begin{array}{l}95 \% \mathrm{Cl} \\
0.39 \text { to } 1.61 \\
0.12 \text { to } 0.36\end{array}$} \\
\hline $\begin{array}{l}\text { Day pulse } \\
\text { pressure }\end{array}$ & $\begin{array}{l}\text { Displacement* } \\
\text { Polygenic h2† }\end{array}$ & & \\
\hline Mean IMT & $\begin{array}{l}\text { Displacement } \\
\text { Polygenic h2 }\end{array}$ & $\begin{array}{l}0.90(0.36) \\
0.20(0.07)\end{array}$ & $\begin{array}{l}0.19 \text { to } 1.61 \\
0.06 \text { to } 0.34\end{array}$ \\
\hline & $\begin{array}{l}\text { Residual } \\
\text { correlation }\end{array}$ & $0.13(0.04)$ & 0.04 to 0.21 \\
\hline
\end{tabular}

*Displacement is expressed in standard deviations between genotype means; †polygenic $h 2$, residual polygenic heritability after accounting for effect of LEPC538T.

$\mathrm{SE}$, standard error

and compared them with non-obese controls; even among studies of "normal" individuals, the average BMI has tended to be higher than in our population (for example, a mean BMI of 29.5 in the study of Jiang et al, compared with 25.4 in the present study). Thus, our findings do not rule out variation in $L E P$ as a cause of obesity, but suggest that such variation does not contribute significantly to the determination of BMI in those classified normal or overweight (BMI 19-29), some $75 \%$ of the UK population. ${ }^{35}$

Our findings may have more general implications. If a substantial proportion of the genetic influence on quantitative traits derives from multiple large displacement rare variants (such as LEPC538T), approaches focused on common variants alone may not be optimal. Though the impact of rare alleles on most quantitative traits has not been systematically evaluated, rare alleles with substantial phenotypic effects were recently shown to contribute significantly to low plasma HDL-C levels in the general population. ${ }^{36}$ At least with respect to $\mathrm{BP}$ and atherosclerosis phenotypes, the present data suggest that full evaluation of both common and rare variants in candidate gene studies may be prudent in order that relatively large effects are not overlooked. With respect to the $L E P$ gene, resequencing in cohorts selected to be extreme for the phenotypes we have studied, and screening of much larger populations (tens of thousands) to confirm the effect of the T allele in TT homozygotes would be important future experiments. Further in vitro and animal model research will also be necessary to discover how the $\mathrm{T}$ allele is involved in the regulation of $\mathrm{BP}$ and atherogenesis susceptibility.

\section{Authors' affiliations}

N Gaukrodger, H Imrie, M Baker, B Keavney, Institute of Human Genetics, University of Newcastle upon Tyne, Newcastle upon Tyne, UK B M Mayosi, H Watkins, M Farrall, Department of Cardiovascular Medicine, University of Oxford, Oxford, UK

P Avery, Department of Statistics, University of Newcastle upon Tyne, Newcastle upon Tyne, UK

J M C Connell, Department of Medicine and Therapeutics, University of Glasgow, Glasgow, UK

This study was funded by the British Heart Foundation, Wellcome Trust, Medical Research Council, Nuffield Foundation, and Pfizer UK Ltd.

Competing interests: none declared. The study sponsors had no role in collection, analysis, or interpretation of the data, or in decisions regarding publication.

*These authors contributed equally to this work.

†Current address: The Cardiac Clinic, Groote Schuur Hospital, Cape Town, South Africa.

Ethics: The investigation corresponds to the principles outlined in the Declaration of Helsinki, and was approved by the appropriate local research ethics committees in Newcastle upon Tyne and Oxford, UK.

\section{REFERENCES}

1 Montague CT, Farooqi IS, Whitehead JP, Soos MA, Rau H, Wareham NJ, Sewter CP, Digby JE, Mohamed SN, Hurst JA, Cheatham KH, Earley AR, Barnett AH, Prins JB, O'Rahilly S. Congenital leptin deficiency is associated with severe early-onset obesity in humans. Nature 1997;387(6636):903-8.

2 Strobel A, Issad T, Camoin L, Ozata M, Strosberg AD. A leptin missense mutation associated with hypogonadism and morbid obesity. Nat Genet 1998;18(3):213-5.

3 Maffei M, Stoffel M, Barone M, Moon B, Dammerman M, Ravussin E, Bogardus C, Ludwig DS, Flier JS, Talley $M$, et al. Absence of mutations in the human $O B$ gene in obese/diabetic subjects. Diabetes 1996;45(5):679-82.

4 Carlsson B, Lindell K, Gabrielsson B, Karlsson C, Bjarnason R, Westphal O, Karlsson U, Sjostrom L, Carlsson LM. Obese (ob) gene defects are rare in human obesity. Obes Res 1997;5(1):30-5.

5 Le Stunff C, Le Bihan C, Schork NJ, Bougneres P. A common promoter variant of the leptin gene is associated with changes in the relationship between serum leptin and fat mass in obese girls. Diabetes 2000;49(12):2196-200

6 Li WD, Reed DR, Lee JH, Xu W, Kilker RL, Sodam BR, Price RA. Sequence variants in the $5^{\prime}$ flanking region of the leptin gene are associated with obesity in women. Ann Hum Genet 1999;63(Pt 3):227-34.

7 Mammes O, Betoulle D, Aubert R, Herbeth B, Siest G, Fumeron F. Association of the G-2548A polymorphism in the $5^{\prime}$ region of the LEP gene with overweight. Ann Hum Genet 2000;64(Pt 5):391-4.

8 Jiang Y, Wilk JB, Borecki I, Williamson S, DeStefano AL, Xu G, Liu J, Ellison RC, Province M, Myers RH. Common variants in the $5^{\prime}$ region of the leptin gene are associated with body mass index in men from the National Heart, Lung, and Blood Institute Family Heart Study. Am J Hum Genet 2004; 75(2):220-30.

9 Lifton RP, Hopkins PN, Williams RR, Hollenberg NK, Williams GH, Dluhy RG. Evidence for heritability of non-modulating essential hypertension. Hypertension 1989;13(6 Pt 2):884-9.

10 Blacher J, Asmar R, Djane S, London GM, Safar ME. Aortic pulse wave velocity as a marker of cardiovascular risk in hypertensive patients. Hypertension 1999;33(5):1111-7.

11 Taniwaki H, Kawagishi T, Emoto M, Shoji T, Kanda H, Maekawa K, Nishizawa Y, Morii H. Correlation between the intima-media thickness of the carotid artery and aortic pulse-wave velocity in patients with type 2 diabetes. Vessel wall properties in type 2 diabetes. Diabetes Care 1999:22(11): 1851-7.

12 Asmar R, Rudnichi A, Blacher J, London GM, Safar ME. Pulse pressure and aortic pulse wave are markers of cardiovascular risk in hypertensive populations. Am J Hypertens 2001;14(2):91-7.

13 Meaume S, Rudnichi A, Lynch A, Bussy C, Sebban C, Benetos A, Safar ME. Aortic pulse wave velocity as a marker of cardiovascular disease in subjects over 70 years old. J Hypertens $2001 ; 19(5): 871-7$.

14 Laurent S, Boutouyrie P, Asmar R, Gautier I, Laloux B, Guize L, Ducimetiere P, Benetos A. Aortic stiffness is an independent predictor of all-cause and cardiovascular mortality in hypertensive patients. Hypertension $2001 ; 37(5): 1236-41$

15 Lewington S, Clarke R, Qizilbash N, Peto R, Collins R. Age-specific relevance of usual blood pressure to vascular mortality: a meta-analysis of individual data for one million adults in 61 prospective studies. Lancet 2002;360(9349): 1903-13.

16 van der Meer IM, Bots ML, Hofman A, del Sol Al, van der Kuip DA, Witteman JC. Predictive value of noninvasive measures of atherosclerosis for incident myocardial infarction: the Rotterdam Study. Circulation 2004; 109(9): 1089-94.

17 Keavney B, McKenzie CA, Connell JM, Julier C, Ratcliffe PJ, Sobel E, Lathrop M, Farrall M. Measured haplotype analysis of the angiotensin-1 converting enzyme gene. Hum Mol Genet 1998;7(11):1745-51.

18 Mayosi BM, Keavney B, Kardos A, Davies CH, Ratcliffe PJ, Farrall M, Watkins $\mathrm{H}$. Electrocardiographic measures of left ventricular hypertrophy show greater heritability than echocardiographic left ventricular mass. Eur Heart J 2002;23(24):1963-71.

19 Keavney B, Bird R, Caiazza A, Casadei B, Conway J. Measurement of blood pressure using the auscultatory and oscillometric methods in the same cuff deflation: validation and field trial of the A\&D TM2421 monitor. J Hum Hypertens 2000;14(9):573-9.

20 Salonen JT, Korpela H, Salonen R, Nyyssonen K. Precision and reproducibility of ultrasonographic measurement of progression of common carotid artery atherosclerosis. Lancet 1993;341(8853): 1158-9.

21 Blankenhorn DH, Selzer RH, Crawford DW, Barth JD, Liu CR, Liu CH, Mack WJ, Alaupovic P. Beneficial effects of colestipol-niacin therapy on the common carotid artery. Two- and four-year reduction of intima-media thickness measured by ultrasound. Circulation 1993;88(1):20-8.

22 Adams MR, Nakagomi A, Keech A, Robinson J, McCredie R, Bailey BP, Freedman SB, Celermajer DS. Carotid intima-media thickness is only weakly correlated with the extent and severity of coronary artery disease. Circulation 1995;92(8):2127-34.

23 O'Connell JR, Weeks DE. PedCheck: a program for identification of genotype incompatibilities in linkage analysis. Am J Hum Genet 1998;63(1):259-66.

24 Abecasis GR, Cherny SS, Cookson WO, Cardon LR. Merlin - rapid analysis of dense genetic maps using sparse gene flow trees. Nat Genet 2002;30(1):97-101

25 Dawson E, Abecasis GR, Bumpstead S, Chen Y, Hunt S, Beare DM, Pabial J, Dibling T, Tinsley E, Kirby $S$, Carter D, Papaspyridonos M, Livingstone $S$, Ganske R, Lohmussaar E, Zernant J, Tonisson N, Remm M, Magi R, Puurand T, 
Vilo J, Kurg A, Rice K, Deloukas P, Mott R, Metspalu A, Bentley DR, Cardon LR, Dunham I. A first-generation linkage disequilibrium map of human chromosome 22. Nature 2002;418(6897):544-8.

26 Abecasis GR, Cardon LR, Cookson WO. A general test of association for quantitative traits in nuclear families. Am J Hum Genet 2000;66(1):279-92.

27 Hasstedt SJ. Variance components/major locus likelihood approximation for quantitative, polychotomous, and multivariate data. Genet Epidemiol 1993; 10(3): 145-58

28 Thomas DC, Clayton DG. Betting odds and genetic associations. J Natl Cancer Inst 2004;96(6):421-3.

29 Misquitta CM, lyer VR, Werstiuk ES, Grover AK. The role of 3'-untranslated region (3'-UTR) mediated mRNA stability in cardiovascular pathophysiology. Mol Cell Biochem 2001;224(1-2):53-67.

30 Huang JL, Gao PS, Mathias RA, Yao TC, Chen LC, Kuo ML, Hsu SC, Plunkett B Togias A, Barnes KC, Stellato C, Beaty TH, Huang SK. Sequence variants of the gene encoding chemoattractant receptor expressed on Th2 cells (CRTH2) are associated with asthma and differentially influence mRNA stability. Hum Mol Genet 2004;13(21):2691-7.
31 Schafer K, Halle M, Goeschen C, Dellas C, Pynn M, Loskutoff DJ, Konstantinides S. Leptin promotes vascular remodeling and neointimal growth in mice. Arterioscler Thromb Vasc Biol 2004;24(1):112-7.

32 Bodary PF, Westrick RJ, Wickenheiser KJ, Shen Y, Eitzman DT. Effect of leptin on arterial thrombosis following vascular injury in mice. JAMA 2002;287(13):1706-9.

33 Karvonen MK, Pesonen U, Heinonen P, Laakso M, Rissanen A, Naukkarinen H, Valve R, Uusitupa MI, Koulu M. Identification of new sequence variants in the leptin gene. J Clin Endocrinol Metab 1998:83(9):3239-42.

34 Shintani M, Ikegami H, Fujisawa T, Kawaguchi $Y$, Ohishi M, Katsuya T, Higaki J, Shimamoto K, Ogihara T. Leptin gene polymorphism is associated with hypertension independent of obesity. J Clin Endocrinol Metab 2002;87(6):2909-12.

35 Department of Health. Health Survey of England 2002. London: The Stationary Office, 2003.

36 Cohen JC, Kiss RS, Pertsemlidis A, Marcel YL, McPherson R, Hobbs HH. Multiple rare alleles contribute to low plasma levels of $\mathrm{HDL}$ cholesterol. Science 2004;305(5685):869-72

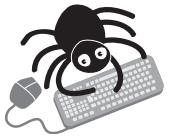

Please visit the Journal of Medical

Genetics website [www. jmedgenet. com] for a link to the full text of this article.
The spectrum of Notch 3 mutations in 28 Italian CADASIL families M T Dotti, A Federico, R Mazzei, S Bianchi, O Scali, F L Conforti, T Sprovieri, D Guidetti, U Aguglia, D Consoli, L Pantoni, C Sarti, D Inzitari, A Quattrone

Background: Cerebral autosomal dominant arteriopathy with subcortical infarcts and leucoencephalopathy (CADASIL) is a cause of hereditary cerebrovascular disease. It results from mutations in the Notch 3 gene, a large gene with 33 exons. A cluster of mutations around exons 3 and 4 was originally reported and limited scanning of these exons was suggested for the diagnosis in most cases.

Objective: To report Notch 3 mutation analysis in 28 unrelated Italian CADASIL families from central and south Italy.

Results: The highest rate of mutations was found in exon $11(21 \%)$ and only $18 \%$ of mutations were in exon 4. This may be related to the peculiar distribution of Notch 3 mutations in the regions of origin of the families.

Conclusions: The results suggest that limited scanning of exons 3 and 4 is inadvisable in CADASIL cases of Italian origin.

A Journal of Neurology Neurosurgery and Psychiatry 2005;76:736-738. 